\title{
ИСТОЧНИКОВЕДЕНИЕ
}

\section{Гуманитарные научные исследования в Бурятии в 1930-1940-е гг.: достижения и проблемы (на материалах Государственного института культуры / Государственного института языка, литературы и истории)}

К 100-летию Института монголоведения, буддологии и тибетологии Сибирского отделения Российской академии наук

\section{Анна Максимовна Плеханова ${ }^{1}$ Цыымсит Пурбуевна Ванчикова ${ }^{2}$}

${ }^{1}$ Институт монголоведения, буддологии и тибетологии СО РАН (д. 6, ул. Сахьяновой, 670047 Улан-Удэ, Российская Федерация)

доктор исторических наук, ведущий научный сотрудник, заместитель директора по научной работе

D 0000-0002-6573-4262.E-mail: plehanova.am@mail.ru

2 Институт монголоведения, буддологии и тибетологии СО РАН (д. 6, ул. Сахьяновой, 670047 Улан-Удэ, Российская Федерация)

доктор исторических наук, главный научный сотрудник

iD 0000-0002-1381-6186. E-mail: vanchikova_ts@mail.ru

(C) КалмНЦ РАН, 2021

(C) Плеханова А. М., Ванчикова Ц. П., 2021

Аннотация. Цель статьи - анализ основных направлений деятельности Бурят-Монгольского государственного института культуры (1929-1936 гг.) / Бурят-Монгольского государственного института языка, литературы и истории (1936-1944 гг.), являющегося преемником первой научной организации Бурятии - Бурят-Монгольского ученого комитета (1922-1929 гг.). Акцент сделан на выявлении достижений и проблем в организации и проведении гуманитарных научных исследований в 1930-1940-е гг. Материалы. Источниковой базой статьи стали неопубликованные документы Центра восточных рукописей и ксилографов ИМБТ СО РАН - ежегодные планы и отчеты о научно-исследовательской работе, протоколы заседаний дирекции, отчеты экспедиций, доклады, тезисы и протоколы заседаний конференций, переписка с различными организациями и учреждениями и другие делопроизводственные материалы, позволившие реконструировать историю реорганизаций научного учреждения, проследить изменения в его научной повестке, выявить результативность научно-исследовательской деятельности. Результаты. Основными направлениями научного поиска в 1930-1940-е гг. являлись исследования в области истории, языка, литературы и искусства бурят-монгольского народа. Археологические экспедиции позволили дать общую характеристику древнейшей истории Бурятии, сформировать первые культурно-исторические схемы. Усилиями историков был собран значительный объем документов по истории 
бурят-монгольского народа, опубликованы материалы по отдельным проблемам дореволюционной Бурят-Монголии, революционного движения и гражданской войны, культуры и просвещения, изданы монографии, составившие классику научных трудов по истории Бурятии. В рамках утвердившихся классово-идеологических установок была проведена дискуссия по спорным вопросам истории Бурят-Монголии, закрепившая однолинейность исторического процесса в бурятоведческих исследованиях. Благодаря успехам бурятского языкознания проведена реформа бурят-монгольской письменности сначала на основе латиницы, а затем - кириллицы. Языковедами Института был внесен определяющий вклад в создание литературного бурятского языка, обогащение его лексического состава, установление единых норм орфографии и грамматики. Сбор, систематизация и изучение устного народного творчества и музыкального фольклора, пополнение фондов Рукописного отдела Института рукописями и ксилографами на тибетском, монгольском, бурят-монгольском языках, улигерами, бурятскими летописями и другими историко-литературными памятниками, переводческая работа - эти и другие направления научно-исследовательской деятельности определяли развитие гуманитарных наук в Бурятии в 1930-1940-е гг. В сложных условиях гонений и репрессий, кадрового дефицита, бытовых проблем сотрудники Института продолжали научный поиск, проводя масштабные исследования социально-политической и экономической истории, культуры и искусства Бурят-Монголии.

Ключевые слова: Бурят-Монгольский ученый комитет, Государственный институт культуры (ГИК), Государственный институт языка, литературы и истории (ГИЯЛИ), Институт монголоведения, буддологии и тибетологии СО РАН (ИМБТ СО РАН), Б. Б. Барадин, И. П. Хабаев, научное учреждение, история Бурятии, археология, фольклор, бурятский язык, латинизация письменности

Благодарность. Статья подготовлена при финансовой поддержке РФФИ в рамках научного проекта № 21-09-43092 «Советская модернизация бурятского общества в 1920-30-е годы».

Для цитирования: Плеханова А. М., Ванчикова Ц. П. Гуманитарные научные исследования в Бурятии в 1930-1940-е гг.: достижения и проблемы (на материалах Государственного института культуры / Государственного института языка, литературы и истории) // Монголоведение. 2021. Т. 13. № 3. С. 450-466. DOI: 10.22162/2500-15232021-3-450-466

\title{
Achievements and Problems of Humanities Research in Buryatia, 1930s-1940s: A Case Study of Buryat-Mongol State Institute of Culture (1929-1936) and Buryat-Mongol State Institute of Language, Literature and History (1936-1944)
}

\author{
Anna M. Plekhanova ${ }^{1}$, Tsymzhit P. Vanchikova ${ }^{2}$
}

${ }^{1}$ Institute for Mongolian, Buddhist and Tibetan Studies, Siberian Branch of the RAS (6, Sakhyanova St., 670047 Ulan-Ude, Russian Federation)

Dr. Sc. (History), Leading Research Associate, Deputy Director for Science

iD 0000-0002-6573-4262. E-mail: plehanova.am@mail.ru

${ }^{2}$ Institute for Mongolian, Buddhist and Tibetan Studies, Siberian Branch of the RAS (6, Sakhyanova St., 670047 Ulan-Ude, Russian Federation)

Dr. Sc. (History), Chief Research Associate

iD 0000-0002-1381-6186.E-mail: vanchikova_ts@mail.ru 
Abstract. The article aims to analyze the principal directions in the activities of Buryat-Mongolian State Institute of Culture (1929-1936) / Buryat-Mongolian State Institute of Language, Literature and History (1936-1944), the successor of the first scientific organization in Buryatia - the Buryat-Mongolian Scientific Committee (1922-1929). It focuses on the achievements and problems in the organization and implementation of scientific research in the humanities in the 1930s. Materials. The sources used are unpublished documents of the Center for Oriental Manuscripts and Xylographs of the IMBT SB RAS, such as annual plans and reports on research work, minutes of meetings of the Directorate, expedition reports, presentations, abstracts and minutes of conferences, correspondence with various organizations and offices, and other materials that were instrumental in reconstructing the history of reorganizations of the scientific institute under study, in following the changes in its scientific program, and in showing its effectiveness and efficiency. Results. In the 1930-1940s, the studies in the field of history, language, literature, and arts of the Buryat-Mongolian people were the principal directions of research in the Institute. Archaeological expeditions were useful in drawing a general picture of the ancient history of Buryatia and the first cultural-historical schemes. Historians' work resulted in publishing a significant number of documents devoted to the history of the Buryat-Mongolian people, the publications included materials on issues of the pre-revolutionary Buryat-Mongolia, the revolutionary movement and the Civil war period, culture, and education, including monographs on the history of Buryatia recognized today as classical scientific works. Within the framework of the established ideological attitudes, there was a discussion on controversial issues of the history of Buryat-Mongolia, which accepted the one-line nature of the historical process in Buryat studies. Thanks to the successes of Buryat linguistics, a reform of the Buryat-Mongolian writing was carried out, first based on the Latin, and then on the Cyrillic alphabet. The linguists of the Institute made a decisive contribution to the elaboration of the literary Buryat language, enriching its lexical resources and standardizing spelling and grammar. Collection, systematization and study of oral folk art and musical folklore, adding to the Manuscript Department of the Institute manuscripts and woodcuts in Tibetan, Mongolian, Buryat-Mongolian languages, as well as uligers, chronicles, and other historical and literary monuments, and translation work - these and other areas of scientific research shaped the development of the humanities in Buryatia in the 1930-1940s. Throughout the period of persecutions and repressions, despite personnel shortage and everyday hardships, the Institute's team continued their work, conducting large-scale studies of the socio-political and economic history, the culture and art of Buryat-Mongolia.

Keywords: Buryat-Mongolian Scientific Committee, State Institute of Culture (GIK), State Institute of Language, Literature and History (GIALI), Institute of Mongolian Studies, Buddhology and Tibetology SB RAS (IMBT SB RAS), B. B. Baradin, I. P. Khabaev, scientific institution, history of Buryatia, archaeology, folklore, Buryat language, Latinization

Acknowledgements. The reported study was funded by RFBR, project no. 21-09-43092 'Soviet Modernization of Buryat Society, 1920s-1930s'.

For citation: Plekhanova A. M., Vanchikova Ts. P. Achievements and Problems of Humanities Research in Buryatia, 1930s-1940s: A Case Study of Buryat-Mongol State Institute of Culture (1929-1936) and Buryat-Mongol State Institute of Language, Literature and History (1936-1944). Mongolian Studies (Elista). 2021; 13 (3): 450-466. (In Russ.). DOI: 10.22162/2500-1523-2021-3-450-466 


\section{Источниковедение}

\section{Введение}

В 2022 г. исполняется 100 лет Институту монголоведения, буддологии и тибетологии Сибирского отделения Российской академии наук (далее - ИМБТ CO РАН), начавшему свою историю с Бурятского ученого комитета (далее Буручком), перед которым был поставлен широкий круг научно-исследовательских задач: изучение национальной культуры, языка, литературы и истории. Несмотря на ограниченность бюджетного финансирования и острый дефицит научных кадров, Буручком достаточно успешно занимался организацией и проведением научных исследований, решая важную задачу создания основ гуманитарных научных исследований в Бурят-Монголии. Однако помимо научно-исследовательской работы, деятельность Буручкома во многом была ориентирована на помощь практической национально-просветительной работе. Научные сотрудники были заняты преимущественно вопросами учебно-методического характера. «Отсутствие плановости и целеустремленности в работе Ученого комитета, распыленность научной работы между разными учреждениями, отсутствие согласованности в их действиях» [Хадалов 1958: 5] поставили на очередь вопрос о создании в Бурят-Монгольской АССР (далее - БМАССР) центрального научно-исследовательского учреждения, в задачи которого входило бы плановое исследование республики: ее народного хозяйства, культуры, языка и истории. В результате с 1928 г. в Буручкоме стал обсуждаться вопрос об изменении его статуса [ГА РБ. Ф. Р-475. Оп. 1. Д. 340. Л. 94]. 12 апреля 1929 г. состоялось совещание, на котором был заслушан доклад директора Иннокентия Петровича Хабаева о реорганизации Буручкома в Научно-исследовательский институт со значительным расширением круга деятельности.

Целью данной статьи являются анализ основных направлений деятельности Института, выявление достижений и проблем в организации и проведении научных исследований в области гуманитарных наук в Бурятии в 1930-1940-е гг.

\section{Материалы исследования}

Источниковой базой исследования стали неопубликованные документы, хранящиеся в Центре восточных рукописей и ксилографов ИМБТ СО РАН. Огромный пласт делопроизводственных материалов (ежегодные планы и отчеты о научно-исследовательской работе отделов и всего Института, докладные записки о состоянии работы, протоколы совещаний, заседаний дирекции, планы и отчеты экспедиций, материалы (протоколы, доклады, тезисы) заседаний конференций, переписка с различными организациями и учреждениями), представленный в фонде 1Б «Буручком. БМГИК. БМГИЯЛИ. БМНИИК ${ }^{1} »$, позволяет реконструировать историю неоднократных реорганизаций научного учреждения, проследить изменения в его научной повестке, выявить результативность научно-исследовательской деятельности.

\section{Буручком - ГИК - ГИЯЛИ: организационные изменения}

12 апреля 1929 г. было принято решение признать правильными основные принципы реорганизации Бурят-Монгольского ученого комитета в Бурят-Монгольский государственный институт культуры [ЦВРК ИМБТ СО РАН. Ф. 1Б.

${ }^{1}$ БМГИК - Бурят-Монгольский государственный институт культуры, БМГИЯЛИ - Бурят-Монгольский государственный институт языка, литературы и истории, БМНИИК— Бурят-Монгольский научно-исследовательский институт культуры. 
Оп. 1. Д. 41. Л. 55]. Согласно одобренному членами совещания Положению, Институт культуры должен был стать «центральным государственным научно-исследовательским учреждением Бурреспублики и содействовать своей деятельностью созданию научной базы для социалистического строительства Бурят-Монгольской республики» [ЦВРК ИМБТ СО РАН. Ф. 1Б. Оп. 1. Д. 41. Л. 60]. После длительных обсуждений были утверждены название института (высказывалась мысль о том, что название «Институт культуры» недостаточно точно определяет сущность работы будущего учреждения, а потому необходимо добавить к наименованию «и производительных сил» [ЦВРК ИМБТ СО РАН. Ф. 1Б. Оп. 1. Д. 41. Л. 54]), определены его структура в составе четырех отделов и круг стоящих перед ними научно-исследовательских задач.

17 мая 1929 г. ЦИК БМАССР и Бюро обкома ВКП(б) закрепили преобразование Бурят-Монгольского ученого комитета в Государственный институт культуры (ГИК) с четырьмя научными отделами - по изучению производительных сил и экономики, истории и этнологии, лингвистики, искусствоведения (позже дополнительно будут созданы сектор марксистско-ленинской литературы и антирелигиозный), научной библиотекой и музеем. В соответствии с Положением о Государственном институте культуры, утвержденным БурЦИКом 17 ноября 1929 г., подчинялся он ЦИК БМАССР. 11 октября 1929 г. состоялось торжественное заседание 2-й сессии БурЦИКа, на котором были сформулированы главные задачи ГИК: «плановое исследование Бурреспублики, ее природных богатств, производительных сил, народного хозяйства, языковой культуры, общественного движения, искусства, этнографии, истории, права» [ГА РБ. Ф. Р-475. Оп. 7. Д. 14. Л. Зоб.]. В отличие от Буручкома он должен был заниматься главным образом научно-исследовательской работой. В 1930 г. было упразднено Научное общество им. Д. Банзарова, а все его фонды переданы Институту культуры.

Согласно Постановлению Президиума ЦИК БМАССР и Бюро Бурят-Монгольского обкома ВКП(б) от 19 марта 1936 г., «в связи с ростом запросов и требований социалистического строительства в республике, в целях усиления научно-исследовательской работы в области истории, языка и литературы Государственный институт культуры реорганизован в Бурят-Монгольский государственный институт языка, литературы и истории (ГИЯЛИ) с оставлением в ведении ЦИК БМАССР» [НА БНЦ СО РАН. Ф. 4. Оп. 1. Д. 1221. Л. 2]. Вследствие слабо заметной работы отдела по изучению производительных сил ГИКа эта задача была исключена из плана работ ГИЯЛИ, в котором было сформировано два сектора: истории; языка и литературы. Сектор искусствоведения был передан «в ведение Управления по делам искусств Наркомпроса БМАССР, сектор марксистско-ленинской литературы — в Бурятское государственное издательство (Бургиз) с непосредственным подчинением отделу пропаганды, агитации и печати Бурят-Монгольского обкома ВКП(б), сектор антирелигиозной пропаганды - в ведение Антирелигиозного музея с передачей последнего в подчинение Наркомпроса» [ЦВРК ИМБТ СО РАН. Ф. 1Б. Оп. 1. Д. 168. Л. 51]. Несмотря на организационные изменения, основными исследовательскими направлениями научного учреждения в 1930-1940-е гг. оставались разработка вопросов истории, языка, литературы и искусства. 


\section{Археология и история. Дискуссия по спорным вопросам истории Бу- рят-Монголии}

В записке Б. Б. Барадина о проекте реорганизации Буручкома в 1929 г. была обоснована необходимость глубокого археологического изучения Бурятии. В науке формировался «устойчивый интерес к древностям Бурятии, рассматриваемой в качестве контактного региона в системе сибирских, байкальских и центральноазиатских культур» [Коновалов 2012: 28]. Были поставлены задачи сбора и изучения «всякого рода памятников старины, относящихся к истории материальной и духовной культуры монгольских племен, а также народностей, населяющих современную Монголию и Бурят-Монголию до заселения их монгольскими племенами», и составления археологических карт и объяснительных записок к ним [Гомбожапов, Коновалов 2021: 157].

На основе материалов Бурят-Монгольской археологической экспедиции АН СССР под руководством Г. П. Сосновского, организованной еще в 19281929 гг. в долинах рек Селенги, Джиды, Чикоя, была дана общая характеристика древнейшей истории Бурятии [Сосновский 1936]. М. М. Герасимов в 1931, 1934-1936 гг. обследовал погребения и стоянки в нижнем течении р. Селенги, приступил к раскопкам Фофановского могильника, открытого в 1926 г. А. П. Окладниковым. Археологическими изысканиями сотрудника краеведческого музея Г. П. Сергеева были охвачены Ацагатские скальные погребения, Сотниковский могильник. Первый бурятский археолог Э. Р. Рыгдылон совершил разведку по долине р. Уды, открыл новые местонахождения петроглифов на p. Кударе [ЦВРК ИМБТ СО РАН. Ф. 1Б. Оп. 1. Д. 161. Л. 3]. Таким образом, в 1930-е гг. целенаправленными экспедиционными исследованиями различных научных центров пополнялся фонд археологических материалов; формировались первые научные концепции и культурно-исторические схемы.

Одним из магистральных направлений научно-исследовательской работы стала разработка вопросов истории Бурят-Монголии. Для обоснования концепции перехода народов, не прошедших капиталистическую стадию, к социализму и идеологической аргументации развернувшихся социалистических преобразований в молодой советской автономии ученым-историкам необходимо был сформировать четкое представление о том, что представляли народы, населяющие территорию Бурятии до Октябрьской революции. В условиях господства марксистско-ленинской идеологии эта проблема фактически была сведена к определению уровня капитализации экономических отношений. Одной из попыток решения данного вопроса стала инициированная властью дискуссия по спорным вопросам истории Бурят-Монголии, которую организовали и провели в июне 1934 г. сотрудники ГИКа.

В процессе полемики выявились разные мнения. С основным докладом выступил П. Т. Хаптаев, который доказывал, что «Бурятия прошла через стадию неразвернутого феодализма со всеми особенностями, свойственными феодализму скотоводческих районов и в связи с ростом городов, местной промышленности и, в особенности, с проведением Сибирской железной дороги была раньше других колоний России приобщена к капиталистической системе хозяйства» [К истории... 1935: 51]. Другую точку зрения высказал М. Ильин, который считал, что в экономике Бурятии «К моменту Октябрьской социалистической революции 
существовали лишь докапиталистические отношения». Однако большинство участников дискуссии (Н. Н. Козьмин, Ф. А. Кудрявцев, О. Дашидондобэ и др.) были солидарны с положениями, выдвинутыми основным докладчиком, и считали, что «в предреволюционной Бурятии капиталистические отношения играли ведущую роль» [К истории... 1935: 51]. Думается, что в докладе и выступлениях некоторых историков «наблюдалась явная тенденция к преувеличению степени развития капиталистических отношений в бурятском улусе» [Плеханова 2011: 19]. Позднее в своей работе «Октябрьская социалистическая революция и гражданская война в Бурятии» П. Т. Хаптаев подчеркивал, что «в хозяйстве аборигенов наряду с буржуазными элементами сохранялись полуфеодальные, а также пережитки патриархально-родового быта» [Хаптаев 1964: 68].

Совещание историков Бурятии 1934 г. определило направление и задачи дальнейших исторических исследований в республике, хотя в целом имело негативные последствия, так как подверглись шельмованию и получили ярлык «буржуазные националисты» видные ученые. Кроме того, в региональной историографии тезис об обреченности до революции народов края на отсталость на долгие годы заслонил необходимость более продуманного определения стартового уровня, с которого началась здесь советская индустриальная модернизация.

Вместе с тем в 1930-е гг. усилиями сотрудников отдела истории был внесен значительный вклад в изучение истории Бурятии. «Соединение интеллектуального и образовательного наследия Б. Барадина, Ц. Жамцарано, Г. Цыбикова и др., а также творческой энергии молодых одаренных историков П. Т. Хаптаева, Б. Д. Цибикова позволило институту уже к середине 1930-х гг. стать одним из центров развития исторической науки в регионе» [Балдано 2012: 66]. Учеными был собран значительный объем документов по истории бурят-монгольского народа, в издаваемых институтом «Записках ГИЯЛИ» опубликованы исследовательские статьи источниковедческого характера и материалы по отдельным вопросам истории дореволюционной Бурят-Монголии, революционного движения и гражданской войны, культуры и просвещения. Важным событием в жизни института стал выход в свет монографий П. Т. Хаптаева [Хаптаев 1936; Хаптаев 1939], А. П. Окладникова [Окладников 1937], В. П. Гирченко [Гирченко 1939], Ф. А. Кудрявцева [Кудрявцев 1940] и других ученых, составивших классику научных трудов по истории Бурятии. Несмотря на преобладание классового подхода, их научная ценность состояла в том, что это были работы по истории народа как этнической общности. Накопленный в этот период материал заложил прочный фундамент для последующих фундаментальных обобщающих работ.

В рамках официального курса на кардинальное преобразование традиционного общества перед институтом была поставлена задача формирования научной основы для антирелигиозной пропаганды. Сотрудники созданного с этой целью сектора занимались составлением антирелигиозного учебника, подготовкой к изданию выпусков журнала «Наука и религия» [ЦВРК ИМБТ СО РАН. Ф. 1Б. Оп. 1. Д. 132. Л. 30об.], читали радиолекции и выступали с докладами на антирелигиозные темы («Отмирание религиозных верований», «Ламство и новая Конституция», «Буддизм на службе японского империализма», «Антипасхальный») в рабочих коллективах и воинских частях [ЦВРК ИМБТ СО РАН. Ф. 1Б. Оп. 1. Д. 159. Л. 36; ЦВРК ИМБТ СО РАН. Ф. 1Б. Оп. 1. Д. 162. 


\section{Источниковедение}

Л. 26], разрабатывали экспозиции для Антирелигиозного музея, публиковали литературу атеистического содержания [Долотов 1932; Тогмитов 1932].

\section{Языкознание. Реформа бурят-монгольского языка и письменности}

Направления научно-исследовательской работы языковедов формировались исходя из целей культурной революции и приоритетов советской языковой политики. Основными задачами в области языкознания были определены «изучение бурят-монгольской языковой культуры с целью повышения ее путем выработки и уточнения литературного стиля, близкого к живым наречиям, а также путем разработки и проведения вопросов реформы письменности, создания научной литературы по всем отраслям монгольского языкознания и т. д.» [ЦВРК ИМБТ СО РАН. Ф. 1Б. Оп. 1. Д. 41. Л. 60об.].

Для преодоления массовой неграмотности населения и встраивания в советское культурное пространство перед учеными была поставлена задача латинизации бурят-монгольской письменности. Предпочтение было отдано латинской графике, поскольку «обращение к русскому алфавиту истолковывалось как возвращение к русификаторской политике царизма» [Базарова 2012: 106]. Решить эту задачу можно было, только предварительно изучив бурятские говоры, прежде мало исследованные. С этой целью при участии Института востоковедения Академии наук СССР был организован ряд экспедиций, собравших богатый и разнообразный материал по говорам бурят в различных районах республики. Экспедиционные обследования, охватившие Агинский (1930), Селенгинский (1931, 1933), Эхирит-Булагатский (1932), Баргузинский (1932), Боханский (1933), Хоринский (1936) аймаки, дали обширный материал для классификации бурятских говоров и выяснения степени их распространенности. Работы по изучению бурятских диалектов позволили приступить к созданию новой общебурятской письменности, основанной на латинской системе графических знаков.

Совещание по латинизации бурят-монгольской письменности, состоявшееся в Верхнеудинске в 1930 г., и Московская лингвистическая конференция 1931 г. в основном разрешили этот вопрос и выработали конкретные мероприятия. Идейными соратниками в борьбе за реформу бурят-монгольского алфавита были известные ученые, руководители Буручкома / ГИКа Б. Б. Барадин и И. П. Хабаев. Открывая орфографическое совещание, состоявшееся в ГИКе в 1930 г., директор И. П. Хабаев убедительно доказывал, что латинизированная бурят-монгольская письменность станет «орудием культурного подъема трудящихся масс и верным средством свершения культурной революции» [ЦВРК ИМБТ СО РАН. Ф. 1Б. Оп. 1. Д. 100. Л. 2]. В основу нового литературного языка сначала было предложено положить халха-монгольское наречие (по мнению Б. Б. Барадина, «халхасское наречие является наиболее совершенным по простоте формы и чистым по лексическому содержанию [ЦВРК ИМБТ СО РАН. Ф. 1Б. Оп. 1. Д. 100. Л. 12], но позднее это решение было квалифицировано как проявление панмонголизма и потому остановились на живом бурят-монгольском наречии селенгинском [Дырхеева, Шагдаров 2021: 134].

С 1931 г. началась практическая работа по переводу монгольской письменности на новый алфавит. При ГИКе была создана специальная терминологическая комиссия, которая имела свой печатный орган — «Бюллетени». Одновременно шла теоретическая работа по вопросам грамматики литературного языка, состав- 
лению школьных учебников и справочных пособий. Латинизация письменности способствовала выделению бурятского языка в самостоятельную единицу. Ее практическими результатами стали перевод обучения на латинизированный алфавит и повышение грамотности в республике. С 1931 по 1936 гг. на новом алфавите были изданы 587 наименований книг [Базарова 2012: 109].

Переход на латинский алфавит стал промежуточным звеном в коренной перестройке бурят-монгольской письменности. На представительной лингвистической конференции, состоявшейся в июле 1936 г. на базе Института культуры, была подвержена критике халхаизация бурятского языка: «главным тормозом в развитии бурят-монгольской письменности и нового литературного языка являлись национал-демократические элементы, которые на протяжении ряда лет вели борьбу за то, чтобы нашу языковую политику свернуть с правильных путей. Главным идеологом их являлся Барадин» [ЦВРК ИМБТ СО РАН. Ф. 1Б. Оп. 1. Д. 175. Л. 5]. Участники конференции приняли решение о необходимости формирования нового литературного языка на основе восточно-бурятского хоринского диалекта, который был признан более понятным для представителей всех других наречий.

На лингвистическом совещании в июле 1938 г. был поставлен вопрос о переводе латинизированной письменности на русский алфавит. Проект нового алфавита на базе русского, разработанный научным сотрудником Института языка, литературы и истории Д. Д. Амоголоновым, 1 мая 1939 г. был утвержден Верховным Советом ССР. Дальнейшая работа языковедов Института была связана с разработкой орфографических правил, подготовкой орфографического словаря и учебных пособий по бурят-монгольскому языку [Амоголонов, Абашеев 1940; Санжеев 1940].

\section{Фольклористика, литературоведение и другие направления научно-ис- следовательской деятельности}

Одним из ведущих направлений в гуманитарных исследованиях в 1930-е гг. являлось филологическое. В круг исследовательских проблем входили сбор, систематизация, изучение и издание богатого фольклорного наследия бурят. Сотрудники Института регулярно направлялись в районы для работы со сказителями. Были записаны в живом бытовании из уст талантливых сказителей, знатоков устного народного творчества разные жанры бурятского фольклора. При участии Института этнографии Академии наук СССР в 1934 г. была организована фольклорная экспедиция под руководством А. М. Астаховой. Большое значение для исследования фольклора восточных бурят имела экспедиция 1937 г. под руководством Г. Д. Санжеева, участники которой «записали значительное количество улигеров, легенд, преданий, пословиц, поговорок, загадок в Еравнинском, Хоринском и Мухоршибирском районах» [ЦВРК ИМБТ СО РАН. Ф. 1Б. Оп. 1. Д. 192. Л. 103-105]. В результате систематического накопления материала Институт смог издать ряд выдающихся произведений дореволюционного фольклора [Гуревич, Элиасов 1939; Сказки 1940].

Изучением музыкального фольклора и проблем развития бурят-монгольской музыкальной культуры занимались сотрудники сектора искусств. В течение ряда лет направлялись экспедиции в Боханский, Аларский, Хоринский, Еравнинский, Агинский, Селенгинский, Мухоршибирский районы (под руководством профес- 


\section{Источниковедение}

сора П. М. Берлинского), собравшие большой материал по народной бурятской музыке и песням. Были записаны музыкальные произведения монгольского певца Лубсан-Хурчи. Эти записи активно использовались бурятским театром и радио. Наряду с научно-исследовательской работой сотрудники Института занимались формированием национального музыкального репертуара, подготовкой кадров музыкальных работников, организацией музыкального радиовещания (подготовка радиопередач «Пойте с нами», «Музыка в массы») [ЦВРК ИМБТ СО РАН. Ф. 1Б. Оп. 1. Д. 156. Л. 15об., 16, 19].

Литературоведы института «для обоснования научной базы для развития социалистической по содержанию и национальной по форме бурят-монгольской культуры» [ЦВРК ИМБТ СО РАН. Ф. 1Б. Оп. 1. Д. 163. Л. 33] сосредоточили свои изыскания на анализе творчества молодых советских писателей Бурятии, исследовали современное состояние бурятской художественной литературы [Хамгашалов 1940].

Большое место в деятельности института занимала переводческая работа, причем не всегда связанная с научной тематикой (перевод марксистско-ленинской литературы). Сотрудниками были переведены на бурят-монгольский язык и изданы такие крупные произведения русской и мировой художественной литературы, как «Мать» М. Горького, «Ревизор» Н. Гоголя, «Отелло» У. Шекспира, «Коварство и любовь» Ф. Шиллера. Сотрудники ГИКа внесли значительный вклад в подготовку кадров издательского дела, организовав при Институте курсы редакторов-переводчиков.

В составе Института действовали научная библиотека, формирование которой началось еще в период деятельности Буручкома, и Рукописный отдел, насчитывающий около пяти тысяч рукописей и ксилографов на тибетском, монгольском, бурят-монгольском языках. В отделе комплектовались персональные фонды общественных деятелей, ученых, писателей, педагогов и др., он активно пополнялся записями сказок, улигеров, имел в своих фондах несколько вариантов эпоса «Гэсэр», богатую коллекцию бурятских летописей, представлявших ценнейшие историко-литературные памятники.

\section{Научные связи}

Институтом культуры по традиции, заложенной Буручкомом, поддерживались тесные связи с Академией наук СССР, Ученым комитетом Монгольской Народной республики, издавались совместные труды («Образцы народной словесности монгольских племен»). Результатом научной кооперации с Институтом востоковедения АН СССР стала публикация бурятских летописей Н. П. Сахарова, Ш. Н Хобитуева, Т. Тобоева, В. Юмсунова и Ю. Ломбоцыренова. Академические научно-исследовательские институты, музеи, специальные комиссии отправляли экспедиции в Бурят-Монголию для исследования ее природных богатств, языка и культуры бурят-монгольского народа. Между Институтом культуры и Всесоюзной ассоциацией сельскохозяйственной библиографии при государственной библиотеке им. В. И. Ленина был заключен 25 декабря 1931 г. договор и 31 декабря 1932 г. дополнительное соглашение на составление «Библиографии Бурят-Монголии». Центральные научные учреждения - Академия наук СССР, Ленинградский и Московский университеты, а также сибирские 
университеты - Иркутский и Томский сыграли большую роль в подготовке научных работников республики.

\section{Проблемы в организации научных исследований}

Наряду с достижениями Институт испытывал определенные трудности в организации научных исследований. Руководство института сетовало на систематическое невыполнение плана научно-исследовательской работы. В 1936 г. ЦИК БМАССР, заслушав отчетный доклад директора Института Д. Д. Донгидона, отметил неудовлетворительное - всего на 23 \% - выполнение годового плана [ЦВРК ИМБТ СО РАН. Ф. 1Б. Оп. 1. Д. 188. Л. 1]. Одной из главных причин трудностей являлась недостаточная квалификация научных работников. В 1935 г. в штате не было ни одного сотрудника, имеющего ученую степень кандидата или доктора наук. В соответствии с Постановлением СНК БМАССР № 271 от 17 апреля 1935 г. при Институте была организована аспирантура по подготовке научных кадров по истории, лингвистике и искусству [ЦВРК ИМБТ СО РАН. Ф. 1Б. Оп. 1. Д. 155. Л. 19]. Однако из-за отсутствия в его составе остепененных сотрудников, способных осуществлять научное руководство диссертационными исследованиями, работа аспирантуры была затруднена. Из 14 штатных сотрудников три человека обучались в аспирантуре, шесть - имели высшее образование, пять - не имели высшего образования. Только один научный сотрудник имел научный стаж свыше пяти лет, восемь - от трех до пяти лет, пять — не имели научного стажа [ЦВРК ИМБТ СО РАН. Ф. 1Б. Оп. 1. Д. 163. Л. 36]. Три человека составляли руководящий персонал учреждения, двое занимали должности старших научных сотрудников, девять - научных сотрудников [ЦВРК ИМБТ СО РАН. Ф. 1Б. Оп. 1. Д. 164. Л. 48]. Большая часть научно-исследовательских работ выполнялась внештатными сотрудниками (из запланированной к разработке в 1937 г. 31 темы (444 авторских листов) на долю внештатных сотрудников приходилось 16 тем (375 авторских листов) [ЦВРК ИМБТ СО РАН. Ф. 1Б. Оп. 1. Д. 167. Л. 36]. Решить кадровую и другие проблемы, по мнению руководства института, можно было, встроив учреждение в систему централизованного научно-организационного руководства путем открытия в БМАССР филиала Академии наук СССР или включения в состав Института Национальностей при ЦИК СССР [ЦВРК ИМБТ СО РАН. Ф. 1Б. Оп. 1. Д. 163. Л. 36, 38].

Решение кадровой проблемы наталкивалось на «квартирный вопрос», обострившийся в 1930-е гг. в связи с развернувшимся в Верхнеудинске/Улан-Удэ промышленным строительством и ростом городского населения. Обследование жилищных условий научных сотрудников и служащих Института культуры, проведенное в марте 1935 г., выявило ряд серьезных проблем: из 22 человек пятеро работников не имели никакого жилья, трое проживали в неудовлетворительных условиях [ЦВРК ИМБТ СО РАН. Ф. 1Б. Оп. 1. Д. 160. Л. 73об.]. Не во всех квартирах сотрудников имелось электричество («отсутствует электроосвещение у Ц. Сампилова», занимающегося художественным творчеством» [ЦВРК ИМБТ СО РАН. Ф. 1Б. Оп. 1. Д. 160. Л. 71]). Отсутствовали необходимые предметы мебели («сотрудник сектора антирелигиозной пропаганды Кочетов проживает в комнате, 6 кв. м., тут же умывальник, книжная полка и столовая < ..> кровати нет, заменена досками на ящиках» [ЦВРК ИМБТ СО РАН. Ф. 1Б. Оп. 1. Д. 160. 


\section{Источниковедение}

Л. 71об.]). В самый разгар реформы письменности «ушел с работы, мотивируя отсутствием квартиры», сотрудник отдела языка Т. А. Бертагаев [ЦВРК ИМБТ СО РАН. Ф. 1Б. Оп. 1. Д. 167. Л. 38-39]. Для снижения остроты вопроса Постановлением ЦИК БМАССР № 359 от 17 февраля 1937 г. Институту в новом строящемся доме Союза писателей было выделено четыре квартиры [ЦВРК ИМБТ СО РАН. Ф. 1Б. Оп. 1. Д. 167. Л. 58].

На эффективности рабочего процесса научного учреждения сказывалась частая смена руководящего состава. Директором института в 1929-1931 гг. был Иннокентий Петрович Хабаев, в 1931-1933 гг. - Бато-Далай Тогмитов, в 1933-1937 гг. - Жамцаран Раднабазарон, в 1937 г. - Дугаржап Доржиевич Донгидон, затем Гомбо Цыбикович Бельгаев, в 1938 г. - Павел Иванович Ханхаев, в 1939-1940 гг.- Павла Ильинична Буртонова, в 1939-1942 гг. - Гомбо Цыбикович Бельгаев.

Институт испытывал большие трудности, вызванные развернувшейся кампанией борьбы с буржуазным национализмом, репрессиями по отношению ко многим научным сотрудникам. Особенности реализации репрессивной политики государства в Бурят-Монгольской СССР были обусловлены этнонациональной спецификой республики. Любые кампании всесоюзного масштаба приобретали здесь еще и националистическую окраску. Уже в 1931 г. бюро обкома ВКП(б) подвергло критике работу Института культуры «за допущение ряда извращений в разработке вопросов языка и искусства, выражавшихся в националистическом уклоне, ориентации отдельных деятелей на теократический Тибет и дореволюционную хановскую Монголию с их феодально-теократической культурой» [Сборник 1932: 24].

В 1937 г. в Бурят-Монголии органами НКВД было инспирировано широко известное дело о так называемой «панмонгольской, контрреволюционной, повстанческо-диверсионной, вредительской организации», по делу которой на 15 февраля 1938 г. было арестовано 2026 человек [Базаров 2007: 10]. Им вменялись в вину подготовка государственного переворота и националистическая обработка населения республики на антисоветской основе, попытка отторгнуть БМАССР от СССР и создать Великое Монгольское государство под протекторатом Японии. Наряду с руководителями республики всех рангов были репрессированы первый директор Буручкома Б. Б. Барадин (на момент ареста - преподаватель монгольского языка Ленинградского института философии, литературы и истории), бывший директор Института (на момент ареста нарком просвещения БМАССР) Д. Д. Донгидон, бывшие директора Института Ж. Раднабазарон и Б. Тогмитов, бывший заместитель директора Института С. Ш. Ширабон, бывший сотрудник Института (на момент ареста - сотрудник газеты «Бурят-Монголой Унэн») Д. Ардин, аспирант АН СССР Б. Болодон и другие ученые, имена которых на протяжении долгого времени были преданы поруганию и забвению. Впоследствии все они были реабилитированы.

Клеветническое обвинение в буржуазном национализме и панмонголизме вызвало глубокое потрясение среди научной интеллигенции. По справедливому мнению В. Ц. Найдакова, «особенно тяжко пострадали восточные народы и их интеллигенция, связанная с цивилизацией и культурой Востока. Они вынуждены были во многом отказаться от национальных корней, от своих традиций, 
верований, обычаев. Многое из культурного наследия, национальных обычаев, традиций было объявлено буржуазным, националистическим, поставлено вне закона» [Найдаков 1995: 8].

Трудно согласиться с выводами, содержащимися в отчете Института за 1937 г.: «В институте орудовали в течение многих лет враги народа, которые проводили вредительскую работу на культурном фронте и немало навредили работе Института. Врагами народа развалена работа Института. Институт, являясь учреждением, разрабатывающим проблемы языка, литературы и истории, не только не дал за время своего существования ни одной сколько-нибудь серьезной работы научного характера, но и не дал ни одного идеологически выдержанного учебного пособия для школ Республики. Научно-исследовательский план из года в год не выполнялся. Это происходило из-за того, что не было руководства работой научных сотрудников и контроля за выполнением работ. Работы кочевали из плана в план и никогда не выходили в свет. Те немногие работы, которые увидели свет, представляют собой идеологический брак, дезориентировавший широкую общественность» [ЦВРК ИМБТ СО РАН. Ф. 1Б. Оп. 1. Д. 194. Л. 1].

В результате чисток и репрессий на 1 января 1938 г. в штате Института состояло 5 человек: директор, заместитель директора, два сотрудника сектора истории, один сотрудник сектора языка (сектор литературы и фольклора остался без штатных сотрудников) [ЦВРК ИМБТ СО РАН. Ф. 1Б. Оп. 1. Д. 194. Л. 2, 4].

В «Кратких пояснениях к плану на 1938 г.» безжалостно констатируется: Институт языка, литературы и истории являлся одним из центров, вокруг которого группировались враги народа. В нем в разное время на руководящих постах в качестве научных работников работало свыше 10 человек, разоблаченных как враги народа (Б. Б. Барадин, Б.-Д. Тогмитов, Д. М. Мункин, П. Н. Дамбинов, Д. Ц. Ардин, Ч.-Л. Базарон, Б.-М. В. Ванданов, А. И. Убугунэ, Б. Ж. Болодон и др.). Работы, выполненные буржуазными контрреволюционными националистами, были забракованы и сняты либо до печатания, либо в процессе печатания. Ряд работ, содержавших ошибочную трактовку вопросов или с просочившимся в них влиянием контрреволюционных националистических концепций, также оказался либо забракованным и снятым, либо задержанным для дополнительного редактирования и просмотра [ЦВРК ИМБТ СО РАН. Ф. 1Б. Оп. 1. Д. 167. Л. 108]. Основными задачами Института на ближайшее время были определены ликвидация последствий вредительства врагов народа в научной работе и определение четкой большевистской линии научной деятельности [ЦВРК ИМБТ СО РАН. Ф. 1Б. Оп. 1. Д. 167. Л. 108].

Дальнейшее развитие Института было сопряжено с трудностями, обусловленными Великой Отечественной войной. Но даже в годы военных испытаний Институт продолжил свою деятельность. Более того, в 1944 г. был открыт сектор экономики, и ГИЯЛИ по постановлению Совета народных комиссаров БМАССР преобразован в Бурят-Монгольский научно-исследовательский институт культуры и экономики (БМНИИКЭ).

\section{Заключение}

Созданный в 1922 г. Бурят-Монгольский ученый комитет (1922-1929 гг.) на протяжении 1930-1940-х гг. претерпел ряд реорганизаций и переименований. Несмотря на организационные изменения, основными исследовательскими 


\section{Источниковедение}

направлениями Государственного института культуры (1929-1936 гг.) / Государственного института языка, литературы и истории (1936-1944 гг.) оставались разработка вопросов истории, языка, литературы и искусства. К организации научно-исследовательской деятельности, разработке научных проблем были привлечены ученые из научных центров Москвы, Ленинграда, Иркутска.

В ходе экспедиционных исследований были открыты новые археологические памятники, дана общая характеристика древнейшей истории Бурятии, сформированы первые культурно-исторические схемы. Были проведены научные конференции и совещания по актуальным проблемам истории. В этот период, характеризующийся отрицанием буржуазной историографии, борьбой со взглядами так называемых «буржуазных националистов», утверждением классовоидеологических установок, состоялась дискуссия по спорным вопросам истории Бурят-Монголии, закрепившая однолинейность подходов в бурятоведении как к отдельным историческим событиям, так и к историческому процессу в целом.

Благодаря успехам бурятского языкознания была проведена реформа бурят-монгольской письменности сначала на основе латиницы, а затем - кириллицы. Одновременно языковедами Института был внесен определяющий вклад в создание литературного бурятского языка, в равной степени понятного всему бурятскому народу, обогащение его лексического состава, установление единых норм орфографии и грамматики, а главное, в условиях огромного диалектного разнообразия бурятского языка выбран диалект, ставший основой литературного языка.

Сбор, систематизация и изучение устного народного творчества и музыкального фольклора, пополнение фондов Рукописного отдела Института рукописями и ксилографами на тибетском, монгольском, бурят-монгольском языках, улигерами, бурятскими летописями и другими историко-литературными памятниками, переводческая работа, причем не всегда связанная с научной тематикой - эти и другие направления научно-исследовательской деятельности определяли развитие гуманитарных наук в Бурятии в 1930-1940-е гг.

Значительные научные результаты в 1930-1940-е гг. были достигнуты благодаря усилиям коллектива научных сотрудников, ставших известными учеными. Среди них - историки П. Т. Хаптаев, Б. Д. Цыбиков; языковеды Т. А. Бертагаев, Д. А. Абашеев, Д. Д. Амоголонов; литераторы и писатели Х. Н. Намсараев, Б. Д. Абидуев, А. М. Хамгашалов и другие ученые.

В сложных условиях гонений и репрессий, кадрового дефицита, бытовых проблем сотрудники Института продолжали научный поиск, проводя масштабные исследования социально-политической и экономической истории, культуры и искусства Бурятии. Направления и тематика научных исследований ГИК / ГИЯЛИ сегодня продолжают активно разрабатываться сотрудниками Института монголоведения, буддологии и тибетологии СО РАН.

\section{Источники}

ГА РБ - Государственный архив Республики Бурятия.

НА БНЦ СО РАН - Научный архив Бурятского научного центра Сибирского отделения РАН.

Сборник 1932 - Сборник директив Бурят-Монгольского ОК ВКП(б) по вопросам национально-культурного строительства. Верхнеудинск: Бургиз, 1932. 52 с. 
ЦВРК ИМБТ СО РАН - Центр восточных рукописей и ксилографов Института монголоведения, буддологии и тибетологии Сибирского отделения РАН.

\section{Sources}

Buryat Scientific Center (SB RAS), Scientific Archive.

Buryat-Mongol Regional Committee of VKP(b): Collected Directives on Ethnic Culture and Ethnicity Construction. Verkhneudinsk: Burgiz, 1932. 52 p. (In Russ.)

Center for Oriental Manuscripts and Xylographs, Institute for Mongolian, Buddhist and Tibetan Studies (SB RAS).

State Archive of the Republic of Buryatia.

\section{Литература}

Амоголонов, Абашеев 1940 - Амоголонов Д. Д., Абамеев Д. А. Орфографический словарь бурят-монгольского языка. Для средних школ. Улан-Удэ: Бурят-монгол гүрэнэй хэблэл, 1940. $277 \mathrm{c.}$

Базаров 2007 - Базаров Б. В., Курас Л. В., Петрушин Ю. А. Репрессивная политика Советского государства в 20-30-е годы XX века (на материалах БМАССР) // Книга памяти жертв политических репрессий в Республике Бурятия. Т. 1. Улан-Удэ, 2007. C. $5-15$.

Базарова 2012 - Базарова В. В. Латинизация Бурят-Монгольской письменности в 1920-х - 1930-х гг. // Власть. 2012. № 8. С. 106-109.

Балдано 2012 - Балдано М. Н. Бурятская историческая наука: от Буручкома до Института монголоведения, буддологии и тибетологии СО РАН // Вестник Бурятского научного центра СО РАН. 2012. № 3(7). С. 65-83.

Гирченко 1939 - Гирченко В. П. Русские и иностранные путешественники XVII, XVIII и первой половины XIX века о бурят-монголах. Улан-Удэ: Бурмонгиз, 1939. 92 с.

Гомбожапов, Коновалов 2021 — Гомбожапов А. Д., Коновалов П. Б. Отдел истории и культуры Центральной Азии - от древности до современности // Вестник Бурятского научного центра СО РАН. 2021. № 3(43). C. 156-163. DOI: 10.31554/22229175-2021-43-156-163

Гуревич, Элиасов 1939 - Гуревич А. В., Элиасов Л. Е. Старый фольклор Прибайкалья. Т. І. Улан-Удэ: Бургиз, 1939. 472 с.

Долотов 1932 - Долотов А. Ламаизм на службе самодержавия и капитализма. Верхнеудинск: Бургиз. 24 с.

Дырхеева, Шагдаров 2021 - Дырхеева Г. А., Шагдаров Л. Д. Отдел языкознания старейший отдел Института РАН // Вестник Бурятского научного центра СО РАН. 2021. № 3(43). C. 133-139. DOI 10.31554/2222-9175-2021-43-133-139

К истории... 1935 - К истории Бурято-Монголии: Материалы дискуссии, состоявшейся в июне 1934 г. в Улан-Удэ. М.; Л.: Соцэкгиз, 1935. 184 с.

Коновалов 2012 - Коновалов П. Б. Археологические исследования в Бурятском научном центре (начало XX - начало XXI в.) // Вестник Бурятского научного центра СО РАН. 2012. № 3(7). С. 26-49.

Кудрявцев $1940-$ Кудрявиев Ф. А. История бурят-монгольского народа от XVII в. до 60-х годов ХІХ в.: Очерки. М.; Л.: Изд-во АН СССР, 1940. 242 с.

Найдаков 1995 - Найдаков В. Ц. О сущности и истории интеллигенции (в порядке дискуссии) // Национальная интеллигенция, духовенство и проблемы социального, национального возрождения народов Республики Бурятия. Улан-Удэ: Олзон, 1995. C. 7-10.

Окладников 1937 - Окладников А. П. Очерки по истории западных бурят-монголов. Л.: ОГИЗ, 1937. 425 с.

Плеханова 2011 - Плеханова А. М. Бурятия в 1920-е гг.: опыт социально-экономической модернизации. Улан-Удэ: Изд-во БНЦ СО РАН, 2011. 441 с. 


\section{Источниковедение}

Санжеев 1940 - Санжеев Г. Д. Синтаксис бурят-монгольского языка. Улан-Удэ: Бургиз, 1940. 146 с.

Сказки 1940 - Сказки Магая (Е. И. Сороковикова). Записи Л. Элиасова и М. Азадовского. Л.: Гослитиздат, 1940. 336 с.

Сосновский 1936 - Сосновский Г. П. Итоги работ Бурят-Монгольского археологического отряда АН СССР в 1928-1929 гг. // Проблемы Бурят-Монгольской АССР. Т. 2. М.; Л.: Изд-во АН СССР, 1936. С. 318-321.

Тогмитов 1932 - Тогмитов Б. Д. Современный ламаизм в Бурятии и задачи дальнейшей борьбы с ним. Верхнеудинск: Бургосиздат, 1932. 48 с.

Хадалов 1958 - Хадалов П. И. Деятельность Института культуры за 35 лет // К 35 -летию Института культуры. Улан-Удэ, 1958. С. 3-56.

Хамгашалов 1940 - Хамгашалов А. М. Опыт исследования бурятско-монгольского стихосложения. Улан-Удэ: Бурмонгиз, 1940. 85 с.

Хаптаев 1936 - Хаптаев П. Т. Краткий очерк истории бурятского народа. Вып. I. Улан-Удэ: Бургосиздат, 1936. 76 с.

Хаптаев 1939 - Хаптаев П. Т. Национальное движение в Бурятии в период первой русской революции. Улан-Удэ: Бурмонгиз, 1939. 150 с.

Хаптаев 1964 - Хаптаев П. Т. Октябрьская социалистическая революция и гражданская война в Бурятии. Улан-Удэ: Бурят. кн. изд-во, 1964. 338 с.

\section{References}

Amogolonov D. D., Abasheev D. A. Orthographic Dictionary of Buryat Mongolian. UlanUde, 1940. 277 p. (In Bur.)

Azadovsky M. (ed.) Folktales Recorded from Magai (E. I. Sorokovikov) by L. Eliasov and M. Azadovsky. Leningrad: Goslitizdat, 1940. 336 p. (In Russ.)

Baldano M. N. Historical science in Buryatia: from Buryat Scientific Committee to the Institute of Mongolian, Buddhist and Tibetan Studies of SD RAS. Bulletin of the Buryat Scientific Center of SB RAS. 2012. No. 3(7). Pp. 65-83. (In Russ.)

Bazarov B. V., Kuras L. V., Petrushin Yu. A. Soviet repressive policies, 1920s-1930s: A case study of the Buryat-Mongol ASSR. In: Memorial Book of Buryatia's Victims of Political Repressions. Vol. 1. Ulan-Ude, 2007. Pp. 5-15. (In Russ.)

Bazarova V. V. Latinization of the Buryat-Mongolian written language, 1920s-1930s. Vlast' (The Authority). 2012. No. 8. Pp. 106-109. (In Russ.)

Dolotov A. Lamaism in the Service of Tsarism and Capitalism. Verkhneudinsk: Burgiz, 1932. 24 p. (In Russ.)

Dyrkheeva G. A., Shagdarov L. D. The Department of Linguistics - the oldest department of the Institute. Bulletin of the Buryat Scientific Center of SB RAS. 2021. No. 3(43). Pp. 133-139. (In Russ.) DOI 10.31554/2222-9175-2021-43-133-139

Girchenko V. P. Russian and Foreign Travelers about Buryat Mongols, $17^{\text {th }}$ to Mid- $19^{\text {th }}$ Century. Ulan-Ude: Burmongiz, 1939. 92 p. (In Russ.)

Gombozhapov A. D., Konovalov P. B. Department of History and Culture of Central Asia from antiquity to modern times. Bulletin of the Buryat Scientific Center of SB RAS. 2021. No. 3(43). Pp. 156-163. (In Russ.)

Gurevich A. V., Eliasov L. E. Old Folklore of the Baikal Region. Ulan-Ude: Burgiz, 1939. 472 p. (In Russ.)

Khadalov P. I. The Institute of Culture and its activities over the 35 years. In: Celebrating the $35^{\text {th }}$ Anniversary of the Institute of Culture. Ulan-Ude, 1958. Pp. 3-56. (In Russ.)

Khamgashalov A. M. A Case Study of Buryat Mongolian Versification. Ulan-Ude: Burmongiz, 1940. 85 p. (In Russ.)

Khaptaev P. T. A Brief Essay on Buryat History. Ulan-Ude: Burgosizdat, 1936. Part I. 76 p. (In Russ.) 
Khaptaev P. T. Ethnic Movement in Buryatia during the First Russian Revolution. Ulan-Ude: Burmongiz, 1939. 150 p. (In Russ.)

Khaptaev P. T. The Great October Socialist Revolution and Russian Civil War in Buryatia. Ulan-Ude: Buryatia Book Publ., 1964. 338 p. (In Russ.)

Konovalov P. B. The archaeological studies at the Buryat Scientific Center, early $20^{\text {th }}-$ late $21^{\text {st }}$ centuries. Bulletin of the Buryat Scientific Center of SB RAS. 2012. No. 3(7). Pp. 26-49. (In Russ.)

Kudryavtsev F. A. History of Buryat Mongols, 1600s-1860s. Collected essays. Moscow; Leningrad: USSR Academy of Sciences, 1940. 242 p. (In Russ.)

Naydakov V. Ts. The essence and history of the intelligentsia: A discussion. In: Ethnic Intellectuals, Clerics, and Problems of Socioethnic Revival in Buryatia. Ulan-Ude: Olzon, 1995. Pp. 7-10. (In Russ.)

Okladnikov A. P. Western Buryat Mongols: Historical Essays. Leningrad: OGIZ, 1937. 425 p. (In Russ.)

Plekhanova A. M. Buryatia, 1920s: The Experience of Socioeconomic Modernization. UlanUde: Buryat Scientific Center (SB RAS), 2011. 441 p. (In Russ.)

Sanzheev G. D. Buryat Mongolian Syntax. Ulan-Ude: Burgiz, 1940. 146 p. (In Russ.)

Shestakov A. V., Lomakin A. I. (eds.) Towards the History of Buryat-Mongolia: Materials of the June 1934 Discussion in Ulan-Ude. Moscow; Leningrad: Sotsekgiz, 1935. 184 p. (In Russ.)

Sosnovsky G. P. Buryat-Mongol Archaeological Expedition, USSR Academy of Sciences: 1928-1929 Activity Report. In: Problems of the Buryat-Mongol ASSR. Vol. 2. Moscow; Leningrad: USSR Academy of Sciences, 1936. Pp. 318-321. (In Russ.)

Togmitov B. D. Contemporary Lamaism in Buryatia and Further Prospects of Its Eradication. Verkhneudinsk: Burgosizdat, 1932. 48 p. (In Russ.) 